\title{
PRIMEIROS APONTAMENTOS SOBRE O ASSÉDIO SEXUAL NO AMBIENTE DE TRABALHO
}

Blumer Vinicius Pachu Silva, Lícia Pimentel Marconi

Universidade do Oeste Paulista - UNOESTE, Curso de Direito, Presidente Prudente, SP. E-mail: blummervinicius@gmail.com

\section{RESUMO}

O presente artigo baseia-se em tema referente ao assedio sexual como conduta recorrente e grave, habitualmente observada no ambiente do trabalho; o aumento de casos, a repercussão psicológica, os prejuízos experimentados pelas partes e a repercussão na esfera moral e patrimonial alertam para a relevância do estudo e discussões sobre o tema no sentido de contribuir para melhorias na relação trabalhista entre empregado e empregador. A identificação da conduta como crime, bem como a atribuição de penalidade ao assediador fazse necessária como forma de intimidar o infrator assim como a adoção de melhores práticas no ambiente de trabalho no sentido de efetivar o combate deste crime. O método de análise aplicado foi o hipotético-dedutivo, por meio de entendimento das leis gerais existentes a respeito do assunto, com pesquisas de cunho histórico, teórico e bibliográfico.

Palavras-chaves: Assedio sexual. Ambiente de trabalho. Crime de assedio.

\section{FIRST POINTS ON SEXUAL HARASSMENT IN THE WORK ENVIRONMENT}

\begin{abstract}
The present article is based on the theme regarding sexual harassment as recurrent and severe behavior, usually observed in the work environment; the increase in cases, the psychological repercussions, the damages experienced by the parties and the repercussion in the moral and patrimonial sphere, point to the relevance of the study and discussions on the subject in order to contribute to improvements in the labor relationship between employee and employer. The identification of conduct as a crime, as well as the attribution of penalty to the harasser is necessary as a way to intimidate the offender as well as the adoption of better practices in the work environment in the sense of effecting the combat of this crime. The method applied was the hypothetico-deductive, through the general laws on the subject, with historical, theoretical and bibliographic research.
\end{abstract}

Keywords: Sexual harassment. Work environment. Crime of harassment. 


\section{INTRODUÇÃO}

O Assédio Sexual é um tema recorrente nos dias atuais, e tem como principal vítima, as mulheres em seu ambiente de trabalho.

A conduta é vista de maneira constrangedora pela vítima, mas para o assediador é como se fosse uma coisa normal, o que faz com que a vítima venha a se calar quando está diante de tal abuso.

Para Eluf (1999, p. 126) “a experiência mostra que "assediar alguém”, em princípio, consiste em fazer propostas de caráter sexual, de forma impositiva ou ameaçadora, importunando ou constrangendo a vítima".

Para caracterizar o assédio sexual, é necessário que haja o pedido de favores sexuais, na forma de cantada com cunho sexual, gestos ou outras formas, que remetem a esse fim, causando o constrangimento do ofendido.

Nas palavras de Bitencourt (2012, p. 171):

A popularização do famigerado assédio sexual, que passou a ter um sentido técnicojurídico específico e bem delimitado - constrangimento (indevido) de subordinado com o intuito de obter favores sexuais -, traz em seu bojo um grande desserviço à sociedade brasileira, vulgarizando a violência sexual: popularmente, os crimes sexuais graves - estupro e atentado violento ao pudor - já estão sendo noticiados pela grande mídia como simples "assédios sexuais.

Como se observa, a vítima, além de suportar a pressão diária da jornada de trabalho, também suporta o constrangimento, a humilhação e o medo de delatar o ato criminoso, por receio de que isso possa influenciar em sua vida profissional, com a perda do emprego.

A gravidade da conduta vai além da forma simplista como ele tem sido tratado.

Este trabalho tem o intuito de analisar a ocorrência do assédio sexual no ambiente de trabalho ou na relação empregatícia, e suas consequências para a vítima e para o assediador, tendo como base o histórico deste instituto, a legislação ordinária e a Constituição ao longo de sua evolução.

O tema em estudo representa uma importância na atualidade tendo em vista sua reiterada ocorrência no âmbito do trabalho.

O objetivo deste estudo foi de caracterizar o crime de assédio sexual no ambiente de trabalho, as formas de ocorrência e os parâmetros legais de combate.

\section{METODOLOGIA}

O estudo realizou-se por meio de pesquisa bibliográfica, usando o método hipotéticodedutivo, leis gerais existentes a respeito do assunto, e o método histórico, para que possamos compreender o ponto de vista da problemática, incluindo-se nesse trâmite, o método comparativo, com base na legislação penal e trabalhista.

Utilizou-se, portanto, a coleta dos dados que nortearam uma possível resolução da problemática apresentada, por meio da doutrina, artigos eletrônicos, leis e jurisprudência; após a realização de tal coleta, respectivos dados foram confrontados, destacando-se as principais ideias com o intuito de chegar o mais aproximo da realidade tecendo considerações plausíveis à problemática apresentada.

\section{RESULTADOS}


Os resultados obtidos com a reflexão do artigo em tela nos remetem a uma discussão sobre a importância da tipificação legal da conduta de assedio sexual, como crime, bem como a penalidade a ser aplicada, como fator intimidatório, no sentido de coibir a reprovável conduta; assim como as necessárias providencias de cunho prático a serem adotadas no âmbito do trabalho como forma de combate ao assedio sexual.

\section{DISCUSSÃO}

A história registra que desde a antiguidade a mulher desempenha o trabalho nas sociedades, confiados a elas trabalhos mais leves, e posteriormente até mesmo o plantio de terras, trabalhavam na ceifa de trigo e até mesmo nas grandes obras de construção.

Alguns trabalhos, por muito tempo, eram confiados somente às mulheres, como é o caso da tecelagem.

Entretanto, em algumas sociedades, a mulher ocupava lugares de destaque desfrutando de certa liberdade (BARROS, 1995).

Os relatos dão conta que, do século $X$ ao século XIV, as profissões comuns aos dois sexos, eram cada vez maiores, com registro de mulheres médicas, escrivãs e professoras.

Já no século XVI o mercado de trabalho para a mulher vai diminuindo, e a partir do século XIX já não tem mais tanta importância, as mulheres passam a desempenhar os trabalhos no ambiente domiciliar.

Ainda no século XIX, o trabalho da chamada "meia força" era solicitada nas indústrias têxtil, era desempenhado por mulheres e pelos menores, porque a mão de obra deles era mais barata e eram mais fáceis de lidar. No entanto, essas mesmas mulheres eram submetidas a trabalhos em ambientes insalubres, trabalhando por horas a fio, sem se quer receber um salário digno, além de serem expostas a um espetáculo de depravação, não se rendendo a sedução de seus superiores (BARROS, 1995).

Com o Tratado de Versailles, em 1919, foi criada a OIT (Organização Internacional do Trabalho), visando melhores condições de trabalho e dar proteção aos trabalhadores. Observando que uma das primeiras matérias a ser regulamentada pelo organismo internacional foi o trabalho da mulher (BARROS, 1995).

No Brasil, como dispõem Calil (2000):

A primeira lei de cunho protecionista à mulher operária surgiria na esfera estadual em São Paulo. A Lei n. 1.596, de 29 de dezembro de 1917, que instituiu o Serviço Sanitário do Estado, proibiu o trabalho de mulheres em estabelecimentos industriais no último mês de gravidez e no primeiro puerpério.

Em meio a tantos problemas enfrentados, o assédio sexual ainda é uma questão que afeta as vítimas interiormente, abalando-a profundamente, desestruturando-a, trazendo reflexos, não só na vida pessoal, emocional, como também, no caso em estudo, no ambiente de trabalho, causando efeitos devastadores

Nas palavras de Jesus (2002, p. 4):

A questão, quando vista sob esta perspectiva, adquire uma dimensão mais alargada, visto que se está tratando de dois significativos e históricos objetos de discriminação: trabalhador e mulher. É certo que o trabalhador do sexo masculino também pode ser sujeito passivo do crime de assédio. Ocorre, entretanto, que a maioria esmagadora das ofensas desse tipo concentra-se nas vítimas do sexo feminino. 
No Brasil, segundo Lopes (2001, p. 13) "sua incidência é preocupante, pois, segundo pesquisas, mais da metade das mulheres, economicamente ativas, alvo principal dos assediadores, já foram assediadas".

Conceituar o assédio sexual é um tanto quanto problemático, não só no Brasil, como no mundo, os conceitos individuais e coletivos mudaram. O que para uns era tido como imoral, que não poderia ser tolerado, hoje é natural e saudável.

Segundo Lopes (2001, p, 15), na visão da OIT (Organização Internacional do Trabalho), o assédio sexual precisa apresentar pelo menos umas dessas características:

1. pode ser uma condição para dar ou manter emprego;

2. influir nas promoções ou na carreira do assediado;

3.prejudicar o rendimento profissional, humilhar, insultar ou intimidar a vítima.

Logo, a definição do Assédio Sexual é a de que ocorre no ambiente de trabalho e desde logo pressupõe uma intimidação por parte do assediador (superior hierárquico), contra o assediado (subordinado), que por estar a um nível acima da vítima exigi-lhe favores muitas das vezes sexuais sob a ameaça de alguma retaliação (LOPES, 2001).

Como destaca Lopes (2001, p. 16):

[...] podemos resumir que, ao assediar, o agente vale-se desde meios sutis, como olhares, gestos, palavras, insinuações, até ataques mais grosseiros como toque importunos, linguagem vulgar e de duplo sentido chegando, até mesmo a claras exigências sexuais.

Os efeitos, resultado desde comportamento, são diversos, atingindo não só a pessoa atacada, mas também toda a relação de trabalho e, consequentemente, o desempenho funcional da empresa.

O Assédio Sexual é um crime com certa dificuldade de ser provado, uma vez que não deixa vestígios, não é uma coisa física como no casso o corpo de delito, existindo apenas a palavra do assediado contra a do assediador, fato que muitas vezes desestimula a denúncia, que uma vez sem provas concretas, o que vigora é a palavra do réu (LOPES, 2001).

Para JESUS (2002, p. 115), podemos usar como elementos caracterizadores básicos do Assédio Sexual:
a) sujeitos: agente (assediador) e destinatário (assediado);
b) conduta de natureza sexual;
c) rejeição à conduta do agente;
d) reiteração da conduta.

Já na visão de Lopes (2001, p. 18), os elementos caracterizadores são:

1. o comportamento é intolerável;

2. é de ocorrência maciça, ou seja, acontece em vários lugares, com expressão significativa;

3. é de grande persistência no tempo, o que significa que não ocorre apensa uma ou duas vezes, mas sim várias vezes, persistindo no tempo.

Tendo o conhecimento de algumas características que configuram o crime, ainda assim é de difícil comprovação, uma vez que dificilmente haverá testemunhas do crime e, palavras e gestos, não deixam rastros (LOPES, 2001). 
A tipificação do crime de Assédio Sexual para fins penais, está prevista no artigo 216 - A do Código Penal, introduzida no dispositivo pela lei 10.244/2001, nos seguintes termos:

Art. 216 - A. Constranger alguém com o intuito de obter vantagem ou favorecimento sexual, prevalecendo-se o agente da sua condição de superior hierárquico ou ascendência inerentes ao exercício de emprego, cargo ou função.

Pena - detenção, de 1 (um) a 2 (dois) anos.

Parágrafo único. (Vetado.)

$\S 2$ 20 A pena é aumentada em até $1 / 3$ (um terço) se a vítima é menor de 18 (dezoito) anos.

Como já sabido, é um crime de difícil comprovação, e, visando o Processo Penal, deixa claro a necessidade de que haja alguma prova material, para que seja objeto de exame.

Deste modo, deve a vítima utilizar-se de meios inominados como apresenta Lopes (apud MIRABETE, 1998, p. 259) "nada impede, portanto, que se utilizem provas com a aplicação de meios técnicos ou científicos, como gravações em fita magnética, fotos, filmes, videofonograma etc., desde que obtidas licitamente".

Assim sendo, não é admitido qualquer meio de prova ilícito que viole os direitos garantidos constitucionalmente, como violação de correspondência, grampo telefônico sem autorização, violação da intimidade, etc., porém, é admissível a vítima que faça uso de meios que permita gravações de conversas entre assediador e assediado, e que terceiros também o faça, desde que autorizado pela vítima (LOPES, 2001).

De acordo com Lopes (2001), a pratica do crime afeta direta e negativamente a empresa como um todo, tanto os funcionários como a produtividade da empresa, por esta razão é que deve se combater esse tipo ação.

No tocante a vítima, Lopes $(2001$, p. 23$)$ a prevenção é seguida por 5 passos:

1. Manter vigilância sobre a própria conduta em relação aos colegas de trabalho.

[...] 2. Vestir-se com modéstia.

[...] 3. Atentar-se às companhias.

[...] 4. Evitar situações comprometedoras.

[...] 5. Não flertar.

Seguir essas regras não traz a segurança de que o assediador não o fará, ainda que a pessoa seja impecável, não inibe a ação.

Mesmo com a ação por parte do assediado, na ânsia de tentar inibir o assediador, pode este não surtir efeito, até mesmo a reclamação ao superior hierárquico, algumas vezes não é de grande ajuda. Nessa hipótese, diante da ineficácia na solução do problema, resolve processar o assediador, o que leva a uma outra discussão (LOPES, 2001).

Como nos diz Nascimento (2011, p. 344):

Há fatos típicos trabalhistas criminalizados pelo direito penal, entre os quais: [...] o crime de assédio sexual (CP, art. 216 - A). Há uma discussão sobre a natureza do denominado direito disciplinar do trabalho, se penal ou não. A empresa, por lei, pode aplicar determinadas sanções ao empregado (advertência, suspensão etc.).

O assédio sexual é caracterizado como o que ocorre entre empregador e subordinado, que envolve relação de poder, pode também se caracterizar entre o preposto do empregador e o subordinado, nesse caso, ocorre a dispensa indireta do assediador por justa causa, a CLT elenca essa possibilidade em seu art. 483 , letra e, "por ato lesivo à honra e a boa fama do 
empregado", uma vez que o diploma não faz menção direta ao assédio sexual (NASCIMENTO, 2011).

Alves (2008) salienta que, no Brasil ainda não se pune especificamente o assédio sexual, e que em todos os casos, se a vitima sofrer o assédio tanto por empregado superior hierárquico quanto pelo empregador cabe a indenização por dano material ou moral.

\section{CONCLUSÃO}

Com os breves apontamentos presentes neste trabalho é possível se observar a frequência da conduta no ambiente de trabalho, sua relevância e necessidade de estabelecer politicas de combate, com base na legislação criminal e disposições legais trabalhistas de indenização a vitima, porem e sobretudo, providencias com relação ao assediador; respectivas políticas de combate passam não só pela legislação como também pelo trabalho preventivo, implantando-se uma política, clara e rígida da não discriminação sexual entre seus empregados, visando propiciar não só um ambiente de trabalho sadio, mas sim, quando tais medidas forem observadas, segundo o autor, o empresário estaria eximindo-se de eventuais responsabilidades com a vítima no que diz respeito a indenizações, levando em conta o comportamento do agente.

\section{REFERÊNCIAS}

ALVES, Gabriel Alexandrino. Assédio sexual: um novo paradigma para o Direito do Trabalho. São Paulo: LTr, 2008.

BARROS, Alice Monteiro de. A mulher e o direito do trabalho. São Paulo: LTr, 1995.

BITENCOURT, Cezar Roberto. Tratado de direito penal, 4: parte especial: Dos crimes contra a dignidade sexual até dos crimes contra a fé. - 6. ed. rev. e ampl. São Paulo: Saraiva, 2012.

BRASIL. Decreto-lei n.o 2.848, de 7 de dezembro de 1940. Código penal, Rio de Janeiro, RJ, 07 dez. 1940. Disponível em: <http://www.planalto.gov.br/ccivil_03/decretolei/Del2848compilado.htm>. Acesso em: 08 de ag. 2018.

CALIL, Léa Elisa Silingowschi. História do direito do trabalho da mulher: aspectos históricossociológicos do início da República ao final deste século. - São Paulo: LTr, 2000.

DAMÁSIO, E. de Jesus e Luiz Flávio Gomes. Assédio Sexual. São Paulo: Saraiva, 2002.

ELUF, Luiza Narib. Crimes contra os costumes. São Paulo: Jurídica Brasileira, 1999.

LOPES, Adriano Almeida. Assédio sexual nas relações do trabalho. Brasília: Consulex, 2001.

MARZAGÃO JR. Laerte I. Assédio sexual e seu tratamento no direito penal. São Paulo: Quartier Latin, 2006. 
NASCIMENTO, Amauri Mascaro. Curso de direito do trabalho: história e teoria geral do direito do trabalho: relações individuais e coletivas do trabalho. 26. ed. São Paulo: Saraiva, 2011. 